06

\title{
Фазовые превращения в оксидах железа под действием микроволнового излучения
}

\author{
() О.Н. Каныгина, В.Л. Бердинский, М.М. Филяк, А.Г. Четверикова, В.Н. Макаров, М.В. Овечкин \\ Оренбургский государственный университет, \\ 460018 Оренбург, Россия \\ I e-mail: KR-727@mail.ru
}

Поступило в Редакцию 4 сентября 2019 г.

В окончательной редакции 6 декабря 2019 r.

Принято к публикации 24 января 2020 г.

Показано, что СВЧ-излучение индуцирует структурные и, как следствие, магнитные фазовые превращения в оксидах железа $\alpha-\mathrm{Fe}_{2} \mathrm{O}_{3}$. В результате микроволнового облучения тонкодисперсных частично аморфизированных частиц оксида железа $\mathrm{Fe}_{2} \mathrm{O}_{3}$ в течение $10 \mathrm{~min}$ во влажной воздушной среде доля кристаллической фазы гематита снижается на 40\%, но при этом общая доля кристаллических составляющих увеличивается изза образования новой ферримагнитной модификации - маггемита $\alpha-\mathrm{Fe}_{2} \mathrm{O}_{3}$. Исходные антиферромагнитные и конечные ферримагнитные образцы оксидов железа представляют собой порошки, состоящие из частиц шарообразной формы с близкими значениями областей когерентного рассеяния рентгеновского излучения $(40-60 \mathrm{~nm})$.

Ключевые слова: полиморфные превращения, оксид железа, дифрактограмма, микроволновое воздействие, вейвлет-анализ.

DOI: $10.21883 /$ JTF.2020.08.49541.308-19

\section{Введение}

СВЧ-воздействие на дисперсную систему как целое вызывает внутри нее множество локальных взаимодействий, которые в совокупности приводят к макроскопическому эффекту. На физико-химические особенности процессов структурообразования оксидных частиц большое влияние оказывают их химический состав и морфология, строение кристаллических решеток, структурные дефекты, ионообменные процессы и т.д.

Значительную долю внимания современных исследователей во всем мире привлекают структурные превращения в оксидных материалах под воздействием микроволновых полей. Если в традиционных технологиях синтеза передача тепла от поверхностных слоев в объем изделия происходит за счет теплопроводности и конвекции, приводя к формированию неоднородной структуры, то в микроволновых полях происходит объемное поглощение энергии веществом, обеспечивающее одновременный равномерный нагрев всего образца. Скорость нагрева не ограничена теплопроводностью, и, следовательно, в принципе возможно формирование по объему требуемой структуры. Многочисленные исследования [1-3], сравнивающие традиционные и микроволновые методы спекания, показывают значительное повышение производительности процесса, снижение энергопотребления. Эти преимущества превращают обработку материалов в СВЧ-полях в эффективный метод, улучшающий свойства оксидных материалов, исключающий загрязнение материала побочными продуктами.

Механизмы взаимодействия оксидных материалов с микроволновыми полями до настоящего времени изу- чены недостаточно, так как подобные исследования, как правило, осуществляются выборочно. Авторы работы [4], в частности, установили, что в оксидах, составляющих глинистые минералы, под воздействием микроволнового излучения происходят фазовые превращения: в оксидах алюминия протекают полиморфные превращения, часть глинозема преобразуется в $\alpha$-корунд. Из четырех модификаций диоксида кремния, содержащихся в природной глине, после микроволнового воздействия в воздушной среде остаются две: $\beta$-кварц и $\beta$-кристобалит, а во влажной среде - только $\beta$-кварц.

Оксиды железа проявляют широкий диапазон магнитных свойств, существенно зависящих от размеров и формы частиц, которые в значительной мере определяются способами их получения. В ряде публикаций [5-9] авторы приводят варианты технологий получения наночастиц маггемита, использующих термические воздействия, методы химической конденсации, пиролиз аэрозолей, синтез частиц по прекурсорной методике.

Для установления закономерностей влияния технологических приемов на морфологию и магнитные свойства частиц оксидов железа необходимо проведение системных экспериментальных исследований, которые позволят понять механизмы структурно-фазовых превращений оксидов железа на наномасштабном уровне и, возможно, управлять их фазовым составом и магнитными свойствами.

Среди различных типов магнитных материалов магнитная керамика обладает рядом преимуществ по сравнению с другими функциональными материалами. Оксид железа может существовать в нескольких фазах гематит, магнетит и маггемит. Магнетит и маггемит - 
два основных оксида железа, которые находят наиболее широкое применение от магнитных записывающих устройств до биомедицинских технологий [5]. Получение подобных материалов с уникальными физикохимическими свойствами является актуальным научнотехническим направлением.

Целью исследования, результаты которого изложены в настоящей работы, являлось изучение структурных откликов оксидов железа на воздействие микроволнового излучения с оценкой возможности получения маггемита из гематита.

\section{Методика эксперимента}

Исходная проба (П0) представляла собой порошок, состоящий из тонкодисперсных (с эффективным диметром менее $30 \mu \mathrm{m})$ частиц оксида железа $\mathrm{Fe}_{2} \mathrm{O}_{3}$ марки ХЧ. Объемная доля аморфной части составляла около $30 \%$, влажность порошка не превышала $0.3 \%$.

Пробу П0 подвергли воздействию микроволнового излучения мощностью $800 \mathrm{~W}$ в течение $10 \mathrm{~min}$ во влажной воздушной среде и получили пробу (П1). Источником поля служила микроволновая система с магнетроном, излучающим на частоте $2.45 \mathrm{GHz}$. Все образцы размещали на вращающейся пластине для усреднения условий воздействия поля.

Для макроанализа дисперсных проб выбрана RGBсистема описания цветового пространства. Изображение в ней состояло из трех компонент - красной Red, зеленой Green и синей Blue. Их сочетание формирует окраску вещества. RGB-система позволила точно идентифицировать цвет по значениям координат и определить долю каждой составляющей колориметрической системы в составе рассматриваемого цвета. Сумма трех основных компонент при максимальной насыщенности дала белый цвет и была принята за единицу. Метод колориметрической градации апробирован на образцах из природной глины [10].

Для съемки изображений использован цифровой микроскоп с камерой высокого разрешения, где $1 \mathrm{~mm}$ изображения сформирован 60 пикселами. Предварительно для данного устройства был создан профайл по следующей схеме: стандартное изображение, содержащее цветные прямоугольники с заранее определенными цветовыми координатами, оцифровывали; в полученном файле определяли соотношение аппаратных данных заранее известным цветовым координатам.

Морфологические изменения проб контролировали методами оптической микроскопии и фрактальной параметрии [11]. В последнее время выросло число публикаций по фрактальному анализу, как инструменту, способному охарактеризовать различные структуры или процессы, происходящие в материалах при образовании этих структур [12,13].

Фрактальный анализ морфологии дисперсных образцов проводили с помощью программы ImageJ и дополни- тельного модуля FracLac 2.5. Определение фрактальной размерности выполняли методом сеток, при котором изображение поверхности объекта разбивали на множество ячеек заданных размеров. Сканирование изображения осуществлялось за несколько циклов, при этом на каждом последующем цикле размеры ячеек сетки увеличивались. Фрактальная размерность определялась по наклону регрессионной линии, рассчитанной методом наименьших квадратов, в координатах $\ln \varepsilon=f(\ln M(\varepsilon))$, где $M(\varepsilon)$ - минимальное число ячеек со стороной $\varepsilon$, необходимых для покрытия всех элементов изображения [14].

Структурные перестройки отслеживали методами рентгенографии. Качественный фазовый состав проб П0 и П1 определяли методом порошковой дифрактометрии на автоматизированном дифрактометре ДРОН-4 с геометрией съемки по Бреггу-Брентано в интервале углов дифракции от 15 до $100^{\circ}$ с использованием $\mathrm{Co} K_{\alpha}$-излучения, используя методику, подробно изложенную в статье [15]. Интерпретировали дифрактограммы с помощью программы LookPDF и картотеки International Centre for Diffraction Data (ICDD). Объемные доли фаз оценивали по интенсивностям трех основных (реперных) линий на дифрактограммах.

Если принять рентгеновский спектр - зависимость интенсивности отраженного пучка от угла дифракции за случайный сигнал, то для его более информативного и достоверного анализа можно применять современные математические методы, в число которых входит и вейвлет-анализ [16]. Применение вейвлетпреобразования к расшифровке дифрактограмм решило проблему выделения маловыраженных, перекрывающихся рефлексов и количественной оценки их истинных параметров [17]. Для графической интерпретации вейвлетпреобразования были использованы линии локальных экстремумов - скелетоны, которые четко показывали структуру исследуемого сигнала и его особенности [18]. Скелетоны - это множество точек на плоскости, в которых находились локальные экстремумы вейвлетпреобразования. Центры тяжести истинных пиков на рентгенограммах лежали на линиях скелетонов.

Средние размеры кристаллитов в частицах, отождествленные с размерами областей когерентного рассеяния (ОКР), согласно [19], оценивали по уширению рентгеновских максимумов в соответствии с методиками, предложенными в работе [20].

Расчет энергии кристаллической решетки маггемита проводили по формуле Борна-Ланде [21]:

$$
U=-\frac{A_{M} N_{a} k Z^{+} Z^{-} e^{2}}{r_{\text {bond }}} \cdot\left(1-\frac{1}{n}\right),
$$

где $Z^{+} e$ и $Z^{-} e-$ заряды положительного и отрицательного иона, $r_{\text {bond }}$ - длина связи для минимальных межионных расстояний, $n-$ показатель Борна, $A_{M}-$ постоянная Маделунга, рассчитанная методом Харрисона [22]. 
Спектры магнитного резонанса для обеих партий образцов регистрировали на малогабаритном автоматизированном ЭПР-спектрометре CMS8400 при комнатной температуре. Условия регистрации спектров ЭПР: частота $9.86 \mathrm{GHz}$, магнитное поле $0.1-0.6 \mathrm{~T}$.

Спектроскопия магнитного резонанса (MP) является специальным применением классической спектроскопии электронного спинового резонанса (ЭПР), где поглощение микроволнового излучения молекулами, ионами или атомами, обладающими электронами с неспаренными спинами, измеряется как функция внешнего поля [23]. В отличие от ЭПР-спектроскопии, МР-спектры „обнаруживают“ связанные спины магнитоупорядоченной системы и отражают сумму всех анизотропных полей и внешнего поля. Уравнение для условия резонанса записали следующим образом:

$$
h v=g_{\text {eff }} \mu_{B} B_{\text {eff }}
$$

где $g_{\text {eff }}$ - эффективный фактор расщепления, $\mu_{B}-$ магнетон Бора, $B_{\text {eff }}$ - эффективное поле как сумма внешнего и внутреннего полей.

\section{Результаты и их обсуждение}

На рис. 1 приведены изображения порошковых проб ПО и П1. На рисунке видно, что влияние СВЧ-излучения проявляется в изменении цвета порошка от красно-оранжевого до темно-коричневого, обусловленном уменьшением значений цветовых компонент Red, Green, Blue, результаты измерений которых приведены в табл. 1.

Из таблицы видно, что после воздействия СВЧ-поля существенно уменьшились все значения цветовых компонент пробы П1, при этом компонента Red — в 2 раза. Такие существенные вариации цветовых компонент связаны с морфологическими и фазовыми превращениями, протекающими в образцах при СВЧ-воздействии.

Изменение морфологии дисперсных частиц отслеживали по оптическим изображениям поверхностей образцов П0 и П1. Размеры и форма частиц после СВЧ-обработки практически не изменились: более $90 \%$ частиц сохранили эффективные диаметры от 1 до $30 \mu \mathrm{m}$, менее $10 \%$ - агломерировали, увеличившись до 90-120 $\mathrm{m}$. Обе партии порошков состояли из частиц шарообразной формы, однако поверхности частиц пробы П1 были покрыты более мелкими частичками. Количественно эти морфологические изменения подтвердились проведенным фрактальным анализом. На рис. 1 видно, что поверхность частиц обеих проб имела развитый рельеф и нерегулярное строение. Рассчитанные значения фрактальных размерностей превосходили топологическую, т.е. поверхности имели фрактальную природу. При этом для пробы П0 она составила 2.83, а пробы П1 - увеличилась до 2.85 , что обусловлено изменением морфологии дисперсных частиц в результате роста фрактальных агломератов.

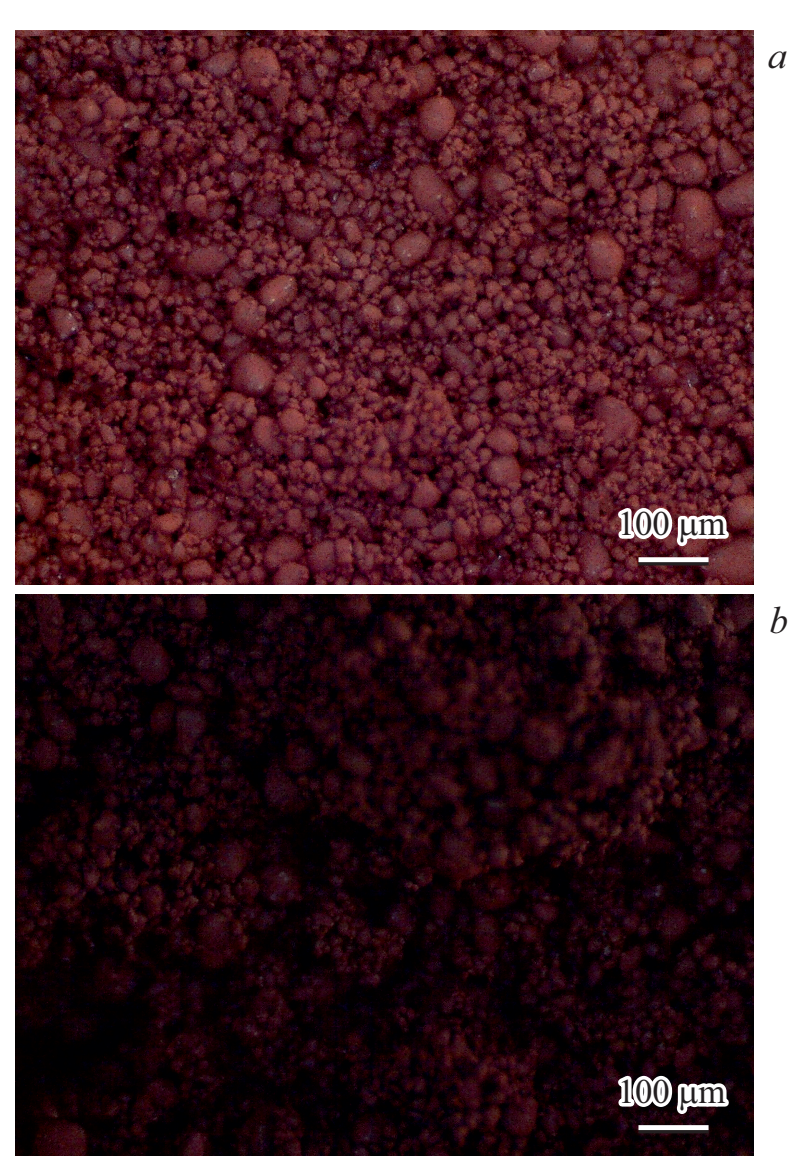

Рис. 1. Изображения поверхности порошка оксида железа $\mathrm{Fe}_{2} \mathrm{O}_{3}$ в исходном состоянии $(a)$ и после СВЧ-воздействия $(b)$.

Таблица 1. Цветовые компоненты изображений частиц оксида железа

\begin{tabular}{c|c|c|c}
\hline Цветовой параметр, \% & П0 & П1 & Изменение цвета, а. u. \\
\hline Red & 39.3 & 17.9 & -0.54 \\
Green & 18.5 & 10.5 & -0.43 \\
Blue & 19.8 & 11.9 & -0.40
\end{tabular}

Мезо- и микроструктурные изменения зачастую являются внешними проявлениями прошедших полиморфных превращений. В их наличии можно убедиться, сравнив дифрактограммы исходных порошков оксида железа (рис. 2,a) и после облучения в СВЧ-поле (рис. 2,b). Обе дисперсные системы содержали значительное количество аморфной фазы, о чем свидетельствовал высокий уровень фона.

При интерпретации результатов измерения дифракционных максимумов были использованы справочные данные для фаз $\alpha-\mathrm{Fe}_{2} \mathrm{O}_{3}, \alpha-\mathrm{Fe}_{2} \mathrm{O}_{3}, \mathrm{Fe}_{3} \mathrm{O}_{4}$ из картотеки ICDD.

Согласно данным рентгенофазового анализа, дифракционные максимумы, выделенные на рис. 2, $a$ (проба П0), полностью соответствовали фазе ромбоэдрического 


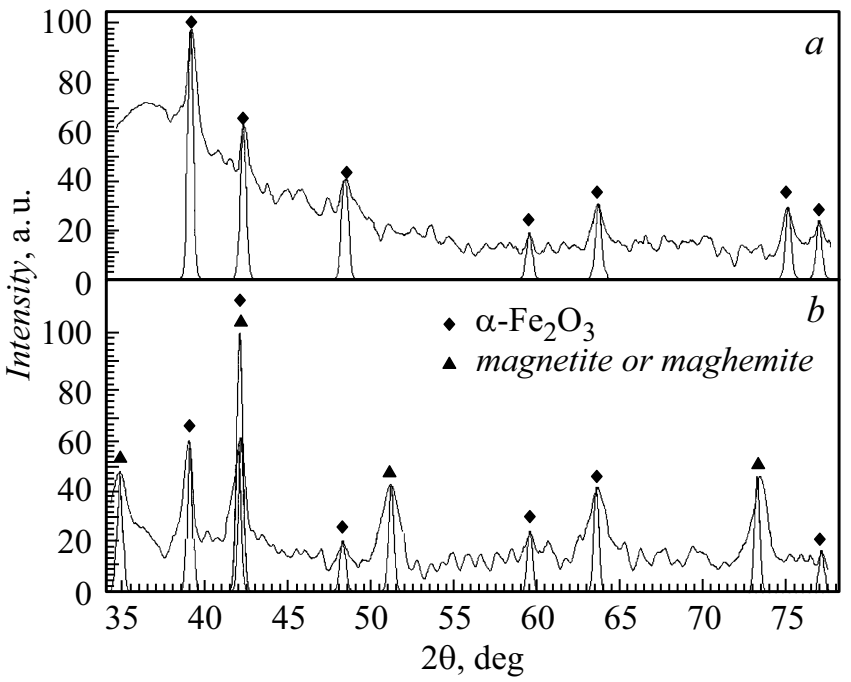

Рис. 2. Дифрактограммы оксида железа в исходном состоянии $(a)$ и после воздействия СВЧ-поля $(b)$.

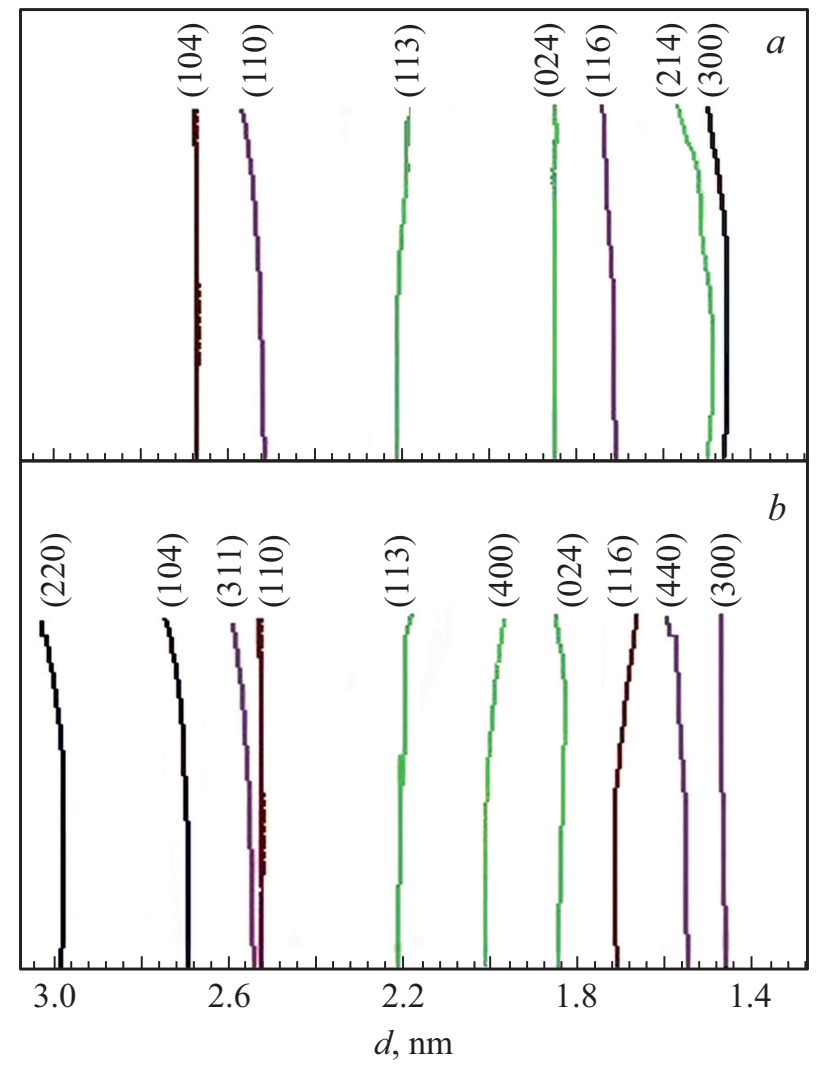

Рис. 3. Скелетоны вейвлет-преобразования дифрактограмм оксида железа в исходном состоянии $(a)$ и после воздействия CBЧ $(b)$.

$\alpha-\mathrm{Fe}_{2} \mathrm{O}_{3}$ (пространственная группа $\left.R \overline{3} c\right)$ с параметрами, $[\mathrm{nm}]: a=0.5038$ и $c=1.3772$. Элементарная ячейка содержала октаэдрически координированные атомы $\mathrm{Fe}^{3+}$ (структура корунда) [24]. После воздействия микроволнового поля из-за фазовых превращений на дифракто-
Таблица 2. Фазовые составы оксида железа до и после воздействия СВЧ-поля

\begin{tabular}{|c|c|c|c|c|c|c|c|}
\hline \multicolumn{4}{|c|}{ ПО } & \multicolumn{4}{|c|}{ П1 } \\
\hline$d, \mathrm{~nm}$ & HKL & $I, \%$ & Фаза & $d, \mathrm{~nm}$ & HKL & $I, \%$ & Фаза \\
\hline & & & & 0.296 & 220 & 46 & Маггемит \\
\hline 0.269 & 104 & 100 & Гематит & 0.269 & 104 & 60 & Гематит \\
\hline & & & & 0.253 & 311 & \multirow{2}{*}{100} & Маггемит \\
\hline 0.252 & 110 & 60 & То же & 0.252 & 110 & & Гематит \\
\hline 0.221 & 113 & 40 & ، $" 6$ & 0.221 & 113 & 20 & " $" ،$ \\
\hline & & & & 0.208 & 400 & 38 & Маггемит \\
\hline 0.185 & 024 & 20 & " $" \omega$ & 0.184 & 024 & 21 & Гематит \\
\hline 0.170 & 116 & 32 & " $" \omega$ & 0.170 & 116 & 35 & " $،$ \\
\hline & & & & 0.152 & 440 & 45 & Маггемит \\
\hline 0.149 & 214 & 29 & " $" \omega$ & & & & \\
\hline 0.146 & 300 & 18 & " $\quad$ " & 0.145 & 300 & 15 & Гематит \\
\hline
\end{tabular}

грамме пробы П1 сместились одни пики и появились новые (рис. 2, $b$ ), которые трудно однозначно идентифицировать, так как они могли быть отнесены к фазам $\mathrm{Fe}_{3} \mathrm{O}_{4}$ (магнетит) и $\gamma$ - $\mathrm{Fe}_{2} \mathrm{O}_{3}$ (маггемит). Обе решетки имели сходные элементарные ячейки.

Магнетит имеет структуру обратной шпинели - гранецентрированную кубическую кристаллическую решетку, основанную на 32 ионах кислорода, с включением 16 трехвалентных ионов железа в тетраэдрических и октаэдрических порах ( $A$ - и $B$-местах, соответственно) и 8 двухвалентных ионов железа в $B$-местах [25]. Маггемит $\gamma$ - $\mathrm{Fe}_{2} \mathrm{O}_{3}$, как и магнетит, имеет обратную шпинельную кристаллическую структуру с той лишь разницей, что в ней отсутствуют двухвалентные ионы железа, что компенсируется наличием вакансий в $B$-местах. Его химическую формулу можно представить в виде [26]:

$$
\left(\mathrm{Fe}_{8}^{\mathrm{III}}\right)\left[\mathrm{Fe}_{40 / 3}^{\mathrm{III}} W_{8 / 3}\right]_{B} \mathrm{O}_{21},
$$

где $W$ - означает вакансию.

Маггемит $\gamma$ - $\mathrm{Fe}_{2} \mathrm{O}_{3}$ изоструктурен магнетиту и образует с ним непрерывный ряд твердых растворов,поэтому выявить все дифракционные максимумы из общего спектра, уточнить их положение и разрешить мультиплетные пики удалось в результате вейвлет-преобразования дифоракторгамм. Линии скелетона дифрактограммы пробы П0 (рис. 3, a) соответствовали межплоскостным расстоянием $d,[\mathrm{~nm}]: 0.269,0.252,0.221,0.185,0.170,0.149$, 0.146 ромбоэдрического $\alpha-\mathrm{Fe}_{2} \mathrm{O}_{3}$. В скелетоне дифрактограммы пробы П1 (рис. 3,b) наблюдались новые линии, относимые к значениям $d, \mathrm{~nm}: 0.296,0.253,0.208$, 0.152 ; они соответствовали кубической сингонии решет- 
Таблица 3. Параметры элементарной ячейки маггемита

\begin{tabular}{c|c|c|c|c|c|c}
\hline Оксид & $n$ & $Z^{+}, Z^{-}, \mathrm{C}$ & $a, \mathrm{~nm}$ & $r_{\text {bond }}, \mathrm{nm}$ & Пространственная группа & $A_{M}$ \\
\hline$\gamma-\mathrm{Fe}_{2} \mathrm{O}_{3}$ & 8.25 & $3^{+}, 2^{-}$ & $0.835[27]$ & 0.182 & $F d \overline{3} m[27]$ & 3.27247
\end{tabular}

ки маггемита $\gamma$ - $\mathrm{Fe}_{2} \mathrm{O}_{3}$ (пространственная группа $F d \overline{3} m$ ) с параметром $a=0.83474 \mathrm{~nm}$.

Установлено, что в результате микроволнового облучения доля кристаллической фазы гематита снизилась на 40\%, но при этом общее количество кристаллических составляющих увеличилось из-за образования новой модификации - маггемита $\gamma-\mathrm{Fe}_{2} \mathrm{O}_{3}$. В результате воздействия СВЧ-поля температура частиц повышалась, в самих частицах происходили полиморфные превращения: часть элементарных ромбических ячеек гематита $\alpha-\mathrm{Fe}_{2} \mathrm{O}_{3}$ перестраивалась в кубические ячейки маггемита $\gamma-\mathrm{Fe}_{2} \mathrm{O}_{3}$. Таким образом, образовалось двухфазное гематит-маггемит метастабильное состояние (табл. 2), в котором объемная доля маггемита составила около 50\% кристаллической составляющей. Приблизительное время обратной релаксации составило около 90 суток.

Линии, полученные под средними углами $\left(2 \theta=50-75^{\circ}\right)$ снимали дополнительно со скоростью $1 / 16^{\circ} / \mathrm{min}$ для определения их полуширины. Средние размеры областей когерентного рассеяния для частиц в пробах П0 и П1 составили $40-60 \mathrm{~nm}$.

Для подтверждения возможности такой перестройки (обратного полиморфного превращения) был проведен расчет энергии кристаллической решетки маггемита с использованием структурных параметров, приведенных в табл 3. Значение показателя Борна для оксидов железа составило 8.25, так как железо находится в восьмой группе четвертого ряда химических элементов. При расчете постоянной Маделунга метод Харрисона был дополнен матричной математической моделью компактного описания кристаллической структуры.

Расчет показал, что удельная энергия кристаллической решетки маггемита $U=13.135 \mathrm{MJ} / \mathrm{mol}$ меньше, чем для гематита $(14.774 \mathrm{MJ} / \mathrm{mol})[28,29]$ и магнетита $(18.788 \mathrm{MJ} / \mathrm{mol})[30]$, следовательно, такое превращение энергетически оправдано.

Полиморфное превращение $\alpha \rightarrow \gamma-\mathrm{Fe}_{2} \mathrm{O}_{3}$ являлось деформационным, происходящим без разрывов химических связей, при небольших изменениях параметров элементарной ячейки. Энергия активации таких процессов мала, поэтому стали возможны „быстрые“ полиморфные превращения, которые сопровождались увеличением длины межионных связей. Перераспределение ионов в решетке маггемита при СВЧ-воздействии, связанное с упорядочением вакансий и ионов $\mathrm{Fe}^{3+}$, привело к появлению магнитных свойств, т.е. наблюдалось фазовое превращение II рода между магнитоупорядоченными состояниями. Согласно [5], магнитные превращения типа порядок-порядок (антиферромагнетизм-

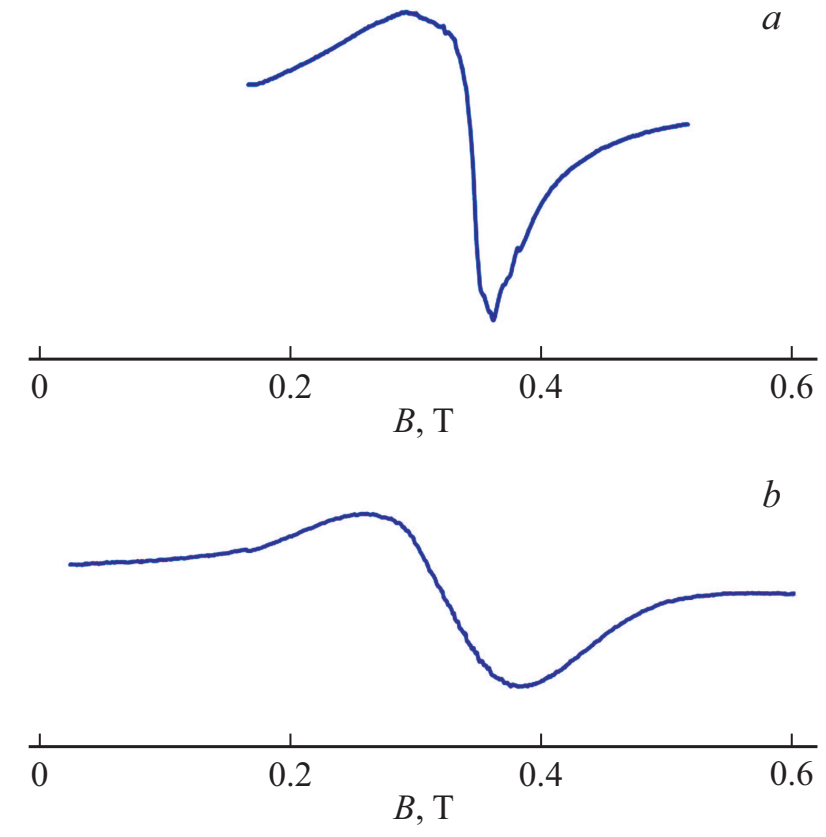

Рис. 4. Спектры магнитного резонанса проб По (a) и П1 (b).

'ферримагнетизм) в тонкодисперсных системах могли происходить при СВЧ-облучении самопроизвольно при температурах, ниже критических, характерных для массивных образцов.

Факт магнитного превращения подтвердился результатами анализа спектров магнитного резонанса. Основными различимыми свойствами фаз оксида железа являлись особенности магнитного поведения, обусловленные вакансиями и валентными состояниями железа в подрешетках [31].

МР-спектр гематита, приведенный на рис. 4, $a$, являлся асимметричным с шириной линии $\delta B \approx 130 \mathrm{mT}$. Значение $g$ составляло 1.98. Асимметричная форма полосы магнитного резонанса, как показано в работе [23], характерна для антиферромагнетиков. Спектр пробы П1, представленный на рис. 4, $b$, также полученный при комнатных температурах, выглядит как широкий симметричный сигнал с $g=2.02$ и шириной линии $(\delta B) \approx 160 \mathrm{mT}$, характерный как для магнетита, так и для маггемита (ферримагнетиков).

Наблюдаемая разница спектров магнитного резонанса гематита и маггемита обусловлена различием их магнитных состояний: исходный гематит являлся неколлинеарным антиферромагнетиком, а маггемит - ярко выраженным ферромагнетиком. 


\section{Заключение}

В процессе воздействия СВЧ-поля тонкодисперсные частицы гематита $\alpha-\mathrm{Fe}_{2} \mathrm{O}_{3}$ претерпевают деформационное полиморфное превращение с образованием маггемита $\gamma-\mathrm{Fe}_{2} \mathrm{O}_{3}$. Влияние СВЧ-излучения проявляется в изменении цвета порошка от красно-оранжевого (проба П0) до темно-коричневого (проба П1), обусловленном уменьшением значений цветовой компоненты Red в 2 раза. Поверхность частиц обеих проб приобретает развитый рельеф. Увеличение фрактальной поверхности проб от 2.83 до 2.85 подтверждает это. Сами частицы состоят из кристаллитов (областей ОКР) размерами $50 \pm 10 \mathrm{~nm}$.

Обе дисперсные системы содержат значительное количество аморфной фазы. Установлено, что в результате микроволнового облучения доля кристаллической фазы гематита снижается на $40 \%$, но при этом общее количество кристаллических составляющих увеличивается из-за образования новой модификации - маггемита $\gamma-\mathrm{Fe}_{2} \mathrm{O}_{3}$. Образуется двухфазное гематит-маггемит состояние, в котором объемная доля маггемита составляет около 50\% кристаллической составляющей. Расчет энергии кристаллической решетки маггемита с использованием структурных параметров показал, что удельная энергия кристаллической решетки маггемита меньше, чем для гематита и магнетита, следовательно, такое превращение энергетически оправдано. Перераспределение ионов в решетке маггемита при СВЧ-воздействии, связанное с упорядочением вакансий и ионов $\mathrm{Fe}^{3+}$, приводит к появлению магнитных свойств, т.е. наблюдается фазовое превращение II рода между магнитоупорядоченными состояниями. Факт магнитного превращения типа порядок-порядок (антиферромагнетизмферримагнетизм) подтверждается результатами анализа спектров магнитного резонанса.

Целесообразна отработка режима СВЧ-облучения частиц $\alpha-\mathrm{Fe}_{2} \mathrm{O}_{3}$ с целью создания технологического контроля количества выхода и магнитных свойств частиц маггемита. Этот способ не требует использования химических реагентов и последующей очистки от них.

\section{Конфликт интересов}

Авторы заявляют, что у них нет конфликта интересов.

\section{Список литературы}

[1] Женжурист И.А. // Стекло и керамика. 2016. № 11. C. 35-39. [Zhenzhurist I.A. // Glass and Ceramics. 2017. Vol. 73. N 11-12. P. 423-426.]

[2] Bykov Y.V., Egorov S.V., Eremeev A.G. Kholoptsev V.V., Plotnikov I.V., Rybakov K.I., Sorokin A.A. // Materials. 2016. Vol. 9. N 8. P. 684-690. DOI: $10.3390 / \mathrm{ma9080684}$

[3] Menezes R.R., Souto P.M., Kiminami R.H.G.A. // Sintering of Ceramic - New Emerging Techniques. 2012. P. 3-23.
[4] Каныгина О.Н., Филяк М.М., Четверикова А.Г. // Неорган. матер. 2018. Т. 54. № 9. C. 955-960. [Kanygina O.N., Filyak M.M., Chetverikova A.G. // Inorgan. Mater. 2018. Vol. 54. N 9. P. 904-909. DOI: 10.1134/S0020168518090042]

[5] Shokrollahi H. // J. Magn. Magn. Mater. 2017. N 426. P. 74-81. http://dx.doi.org/10.1016/j.jmmm.2016.11.033

[6] Салихов С.В., Савченко А.Г., Гребенников И.С., Юртов Е.В. // Изв. РАН. Сер. физ. 2015. Т. 79. № 9. C. 1251-1258. [Salikhov S.V., Savchenko A.G., Grebennikov I.S., Yurtov E.V. // Bull. Rus. Academ. Sci.: Physics. 2015. Vol. 79. N 9. P. 1106-1112.]

[7] Никифоров В.Н., Гольдт А.Е., Гудилин Е.А., Средин В.Г., Ирхин В.Ю. // Изв. РАН. Сер. физ. 2014. Т. 78. № 10. C. 1330-1335. [Nikiforov V.N., Goldt A.E., Gudilin E.A., Sredin V.G., Irhin V.Y. // Bull. Rus. Academ. Sci.: Physics. 2014. Vol. 78. N 10. P. 1075-1080.]

[8] Moran E. Morán E., Blesa M.C., Tornero J.D., Nieves Menéndez, M-Eloisa Medina // Inorgan. Chem. 2002. Vol. 41. N 23. P. 5961-5967.

[9] Wu W., Xiao X.H., Zhang S.F., Peng T.C., Zhou J., Ren F,, Jiang C.Z. // Nanoscale Res. Lett. 2010. N 5. P. 1474-1479. https://doi.org/10.1007/s11671-010-9664-4

[10] Четверикова А.Г., Каныгина О.Н. // Измерительная техника. 2016. № 6. С. 44-47. [Chetverikova A.G., Kanygina O.N. // Measurement Techniques. 2016. N 59. P. 618-622. DOI: $10.1007 / \mathrm{s} 11018-016-1019-9]$

[11] Четверикова А.Г., Каныгина О.Н., Филяк М.М., Савинкова Е.С. // Измерительная техника. 2017. № 11. C. 27-31. [Chetverikova A.G., Kanygina O.N., Filyak M.M., Savinkova E.S. // Measurement Techniques. 2018. Vol. 60. N 11. P. 1109-1115. DOI: $10.1007 / \mathrm{s} 11018-018-1326-4]$

[12] Колмаков А.Г., Солнщев К.А., Витязь П.А., Ильюшенко А.Ф., Хейфеи, М.Л., Баринов С.М. // Материаловедение. 2012. № 9. C. 37-45. [Kolmakov A.G., Solntsev K.A., Vityaz P.A., Il'Yushchenko A.F., Kheifets M.L., Barinov S.M. // Inorganic Mater: Appl. Res. 2013. Vol. 4. N 4. P. 322-327. DOI: $10.1134 / \mathrm{S} 2075113313040059]$

[13] Каныгина О.Н., Четверикова А.Г., Филяк М.М., Огерчук A.A. // Стекло и керамика. 2015. № 12. С. 1116. [Kanygina O.N., Chetverikova A.G., Filyak M.M., Ogerchuk A.A. // Glass and Ceramics. 2016. Vol. 72. N 11. P. 444-448. https://doi.org /10.1007/s10717-016-9807-x]

[14] Мандельброт Б. Фрактальная геометрия природы / Пер. с англ. М.: Ин-т компьютерных исслед., 2002. 656 с.

[15] Красильников В.Н., Гырдасова О.И., Тютюнник А.П., Дьячкова Т.В., Бакланова И.В., Марченков В.В., Доможсирова А.Н., Бамбуров В.Г. // ДАН. 2018. Т. 481. № 4. C. 386-390. [Krasil'nikov V.N., Gyrdasova O.I., Tyutyunnik A.P., Diachkova T.V., Baklanova I.V., Bamburov V.G., Marchenkov V.V., Domozhirova A.N. // Doklady Chem. 2018. Vol. 481. N 2. P. 161-165.]

[16] Астабьева Н.М. // УФН. 1996. Т. 166. № 11. С. 1145 1150. [Astaf'eva N.M. // Physics-Uspekhi. 1996. Vol. 39. N 11. P. 1085-1108. DOI: http://dx.doi.org/10.1070/PU1996v039n11ABEH000177]

[17] Лазоренко О.В., Лазоренко С.В., Черногор Л.Ф. // Радиофизика и радиоастрономия. 2007. Т. 12. № 2. С. 182-204. [Lazorenko O.V., Lazorenko S.V., Chernogo L.F. // Radio Phys. Radio Astronomy. 2007. Vol. 12. N 2. P. 182-204]

[18] Gregoire J.M., Darren Dale, Bruce van Dover R. // Rev.. Scien. Instrum. 2011. N 82. P. 015105-1-015105-8. https://doi.org/10.1063/1.3505103 
[19] Гусев А.И., Курлов А.С. // Металлофизика и новейшие технологии. 2008. Т. 30. № 5. С. 679-694.

[20] Бузимов А.Ю., Кульков С.H., Gӧmze L.A., Géber R., Kocserha I. // Перспективные материалы. 2018. № 4. C. 31-39. DOI: 10.30791/1028-978X-2018-4-31-39

[21] Хьюи Д. Неорганическая химия. Строение вещества и реакционная способность / Пер. с англ. Под. ред. Б.Д. Степина, Р.А. Лидина. М.: Химия, 1987. 696 с.

[22] Harrison W.A. // Phys. Rew. B. 2006. N 73. P. 212103-1-212103-2.

[23] Gehring A.U., Fischer H., Louvel M., Kunze K., Weidler P.G. // Geophys. J. Intern. 2009. N 179. P. 1361-1371.

[24] Cox D.E., Takei W.J., Miller R.C., Shiraneet G. // J. Phys. Chem. Sol. 1962. Vol. 23. N 7. P. 863-874.

[25] Алексеев В.П., Рыбникова Е.В., Шипилин М.А. // Вестник ЯрГУ. Сер. Естественные и технические науки. 2012. № 4. C. $10-18$.

[26] Stucki J.W., Goodman B.A., Schwertmann U. Iron in Soils and Clay Minerals. Cityplace Dordrecht: Reidel Publishing Company, 1988. 893 p.

[27] Jorgensen J.-E., Mosegaard L., Thomsen L.E., Jensen T.R., Hanson J.C. // J. Sol. State Chem. 2007. N 180(1). P. 180-185.

[28] Lailong Mu, Changjun Feng, Hongmei He // Match Commun. Mathem. Comput. Chem. 2006. N 56. P. 97-111.

[29] Pecharromán C., González-Carreño T., Iglesias J.E. // Phys. Chem. Minerals. 1995. Vol. 22. N 1. P. 21-29.

[30] Glasser L. Lattice // Inorganic Chem. 1995. N 34(20). P. 4935-4936.

[31] Musa Mutlu Can, Mustafa Coskun, Tezer Firat // J. Alloys Comp. 2012. N 542. P. 241-247

http://dx.doi.org/10.1016/j.jallcom.2012.07.09131 